\title{
Physical map of the chromosome of Aeromonas salmonicida and genomic comparisons between Aeromonas strains
}

\author{
Elizabeth Umeloł and Trevor J. Trust $\ddagger$
}

Department of Biochemistry and Microbiology and Canadian Bacterial Diseases Network, University of Victoria, Victoria, BC, V8W $3 P 6$ Canada
Author for correspondence: Elizabeth Umelo. Tel: +1 604822 4417. Fax: +1 6048226041. e-mail: umelo@interchange.ubc.ca

\begin{abstract}
I-Ceul and Pmel physical maps of the Aeromonas salmonicida A449 chromosome were constructed using PFGE. The circular chromosome of A. salmonicida A449 was estimated to be $4658 \pm 30 \mathrm{~kb}$. The approximate location of several genes, including those encoding proteins implicated in virulence, were identified. The map showed that the known virulence-factor-encoding genes were not clustered. The I-Ceul genomic digestion fingerprints of several typical and atypical strains of A. salmonicida were compared. The results confirmed the homogeneity of typical strains, which provided further support for the clonality of the population structure of this group. Extensive diversity was observed in the I-Ceul digestion fingerprint of atypical strains, although a clonality was observed in the strains isolated from diseased goldfish. The results suggest that comparison of I-Ceul digestion fingerprints could be used as a powerful taxonomic tool to subdivide the atypical strains and also help clarify some of the current confusion associated with the taxonomy of the genus Aeromonas.
\end{abstract}

Keywords: Aeromonas salmonicida, physical map, genetic map, circular chromosome, genome comparison

\section{INTRODUCTION}

Aeromonas salmonicida is a fish-pathogenic bacterium. A number of virulence-implicated factors have been identified in $A$. salmonicida, such as the paracrystalline tetragonal surface protein array (A-layer), several proteases and haemolysins, a glycerophospholipid cholesterol acyl transferase and LPS (reviewed by Noonan $\&$ Trust, 1995a). Although the genes encoding some of these factors have been cloned, sequenced and characterized, nothing is known about their location or organization on the chromosome.

Strains of A. salmonicida are broadly grouped either as typical or atypical, depending on several genotypic and phenotypic properties (Austin \& Austin, 1993; Belland \& Trust, 1988). The typical strains cause the septicaemic disease furunculosis in salmonids and are reported to be

†Present address: Department of Microbiology and Immunology, 3006174 University Boulevard, University of British Columbia, Vancouver, BC, V6T 123 Canada.

‡Present address: Astra Research Center Boston Inc., 128 Sidney St, Cambridge, MA 01770, USA. a homogeneous group (Austin \& Austin, 1993; Belland $\&$ Trust, 1988). The nutritionally fastidious atypical strains cause different types of diseases in a variety of fish and are very heterogeneous. The heterogeneity of atypical strains has made the subclassification of this group difficult. Indeed the atypical $A$. salmonicida strains grouped under the subspecies nova have been reported to have potential for further subdivision (Belland \& Trust, 1988). The taxonomy of the genus Aeromonas as a whole is riddled with significant confusions because of poor correlation between results obtained using different classification methods (Austin et al., 1989; Wilcox et al., 1992). Austin and co-workers have suggested that the problems inherent in the current classification methods need to be addressed before a definitive classification for the genus Aeromonas can be made (Austin \& Austin, 1993). Hence the need for better classification tools for the genus cannot be overemphasized.

PFGE, which allows the resolution of megabase-sized DNA molecules (Schwartz et al., 1983), has made it possible to construct genome maps of numerous microorganisms. Using PFGE technology, the physical maps of organisms such as Escherichia coli (Smith et al., 
1987), several Salmonella species (Liu et al., 1993a), Streptomyces species (Lin et al., 1993) and Borrelia burgdorferi (Casjens \& Huang, 1993) have been determined. These were constructed by ordering high molecular mass genomic DNA fragments obtained following digestion with rare cutting restriction enzymes and separation by PFGE.

In this study, we have used PFGE and Southern blotting analysis to determine the physical and genetic map of the $A$. salmonicida A449 chromosome. Genes of $A$. salmonicida, including those encoding proteins implicated in virulence, were localized on the map. The I$\mathrm{CeuI}$ digestion fingerprints of several typical and atypical strains of $A$. salmonicida, including representative strains from other Aeromonas species, were compared. The use of the I-CeuI digestion fingerprint as a taxonomic tool for Aeromonas was also investigated.

\section{METHODS}

Bacterial strains, vectors and growth conditions. The strains and vectors used in this study are listed in Table 1. All strains were cultured on trypticase soy agar or broth (TSA or TSB; BBL). Atypical strains of $A$. salmonicida were cultured on TSA supplemented with $5 \%$ horse blood or in TSB supplemented with $10 \mu \mathrm{g}$ haemin $\mathrm{ml}^{-1}$. The Aeromonas strains were grown at $20^{\circ} \mathrm{C}$ for $24-36 \mathrm{~h}$ while $E$. coli strains were grown at $37^{\circ} \mathrm{C}$ for $18 \mathrm{~h}$. Antibiotics were used at the following concentrations $\left(\mu \mathrm{g} \mathrm{ml}^{-1}\right)$ : ampicillin, 100; chloramphenicol, 180.

Preparation of intact genomic DNA. Aeromonas strains were grown in $10 \mathrm{ml}$ TSB to an $\mathrm{OD}_{600}$ of 45 using the red 66 filter of the Klett-Summerson Photoelectric Colorimeter, model 8003 , corresponding to approximately $1.5 \times 10^{8}$ c.f.u. $\mathrm{ml}^{-1}$ and a yield of $10 \mu \mathrm{g}$ DNA (Smith et al., 1988). Chloramphenicol was added and the culture was grown for a further $1 \mathrm{~h}$ and then chilled on ice for $10 \mathrm{~min}$. The cells were harvested and washed

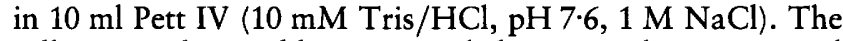
cells were thoroughly resuspended in $1.6 \mathrm{ml}$ Pett IV and warmed to $37^{\circ} \mathrm{C}$. An equal volume of $1 \%(\mathrm{w} / \mathrm{v}$ ) low-meltingpoint agarose (Bio-Rad) warmed to $37^{\circ} \mathrm{C}$ was added to the cells and the sample was mixed. The mixture was dispensed into $1 \mathrm{ml}$ syringes and allowed to solidify at room temperature for at least $2 \mathrm{~h}$. The agarose moulds containing the cells were pushed out of the syringes approximately $50 \mu \mathrm{l}$ at a time and each small cylinder (insert) was sliced off with a scalpel. The inserts were placed into $6 \mathrm{ml} \mathrm{EC} \mathrm{lysis} \mathrm{solution}(6 \mathrm{mM}$ Tris/HCl, pH 7.6, $1 \mathrm{M} \mathrm{NaCl}, 100 \mathrm{mM}$ EDTA, pH 8.0, 0.5\% Brij-58, $0 \cdot 2 \%$ deoxycholate, $0.5 \%$ Sarkosyl) containing $1 \mathrm{mg}$ lysozyme ml-1 and $20 \mu \mathrm{g} \mathrm{RNase} \mathrm{ml}^{-1}$ and incubated at $37^{\circ} \mathrm{C}$ overnight with shaking. The EC solution was replaced with $6 \mathrm{ml}$ ESP solution (0.5 M EDTA, pH 9-9.5, $1 \%$, w/v, lauryl

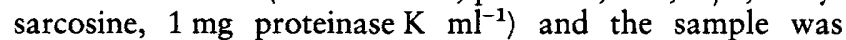
incubated at $50^{\circ} \mathrm{C}$ for $48 \mathrm{~h}$ with shaking. The ESP solution was removed and the inserts were first incubated twice in $10 \mathrm{ml} \mathrm{TE}$ (10 mM Tris/ $\mathrm{HCl}, \mathrm{pH} 7 \cdot 4,0.1 \mathrm{mM}$ EDTA) containing $1 \mathrm{mM}$ PMSF for $2 \mathrm{~h}$ and then three times in $10 \mathrm{ml} \mathrm{TE}$ for $2 \mathrm{~h}$ without PMSF. The inserts were stored in TE at $4{ }^{\circ} \mathrm{C}$ until use.

Restriction enzyme digestion and end-labelling of I-Ceul fragments. For complete DNA digestion with I-CeuI and $P m e I$, each insert was first incubated in $100 \mu \mathrm{l} 2 \times$ NEB buffer (New England Biolabs) for I-CeuI digestion or $2 \times$ NEB buffer
4 for PmeI digestion for $15 \mathrm{~min}$ on ice. The solutions were replaced with $100 \mu \mathrm{l} 1 \times \mathrm{NEB}$ buffer containing $2 \mathrm{U}$ I-CeuI for I-CeuI digestion and $1 \times$ NEB buffer 4 containing $5 \mathrm{U} P m e I$ for PmeI digestion, followed by a $15 \mathrm{~min}$ incubation on ice. Complete digestion of A449 genomic DNA was carried out at $37^{\circ} \mathrm{C}$ for $4 \mathrm{~h}$. For PacI digestion, inserts were incubated twice in $100 \mu \mathrm{l} 1 \times \mathrm{NEB}$ buffer 1 for $30 \mathrm{~min}$ on ice. A fresh $100 \mu \mathrm{l}$ of $1 \times$ NEB buffer 1 containing $10 \mathrm{U}$ PacI was added to the insert and incubated at $4{ }^{\circ} \mathrm{C}$ overnight. Digestion was conducted at $37^{\circ} \mathrm{C}$ for at least $4 \mathrm{~h}$. For partial I-CeuI digestion of A449 genomic DNA, digestion was terminated after $40 \mathrm{~min}$ at $37^{\circ} \mathrm{C}$. After PFGE separation, the partially digested DNA fragments were excised from the gel under low wavelength UV light and then digested to completion with I-CeuI. After digestion, the DNA within the agarose pieces was end-labelled by blunt-ending the $5^{\prime}$-terminal I-CeuI overhangs using Klenow DNA polymerase and radioactive dNTPs. Each piece of agarose was first incubated in $100 \mu \mathrm{l} 1 \times$ Klenow buffer (New England Biolabs) on ice for $20 \mathrm{~min}$. The buffer was replaced with a fresh $100 \mu \mathrm{l} 1 \times$ Klenow buffer containing $10 \mu \mathrm{Ci}(370 \mathrm{kBq})$ each of $\left[\alpha^{-32} \mathrm{P}\right] \mathrm{dATP}$ and $\left[\alpha^{32} \mathrm{P}\right] \mathrm{dTTP}$ (Amersham), $2 \mathrm{mM}$ dCTP, $2 \mathrm{mM}$ dGTP and $5 \mathrm{U}$ Klenow DNA polymerase and the sample was incubated on ice for $20 \mathrm{~min}$. The end-labelling reaction was conducted at $18^{\circ} \mathrm{C}$ for $2 \mathrm{~h}$ and the labelled DNA fragments were separated by PFGE. After separation, the gels were dried and exposed to X-OMAT AR film (Kodak).

PFGE conditions. DNA samples were analysed using the CHEF-DRRII PFGE system (Bio-Rad) connected to a model 1000 Mini chiller (Bio-Rad) to keep the buffer temperature at $14^{\circ} \mathrm{C}$. TBE buffer $(0.5 \times: 45 \mathrm{mM}$ Tris $/ \mathrm{HCl}, 45 \mathrm{mM}$ borate, $1.0 \mathrm{mM}$ EDTA, $\mathrm{pH} 8.3$ ) and $0.7-1 \%$ agarose gels supplemented with $1.5 \mu \mathrm{g}$ ethidium bromide $\mathrm{ml}^{-1}$ were utilized in the separation of DNA. Using the long gel cast $(21 \times 14 \mathrm{~cm}$; Bio$\mathrm{Rad}$ ), both $\mathrm{PmeI}$ and I-CeuI digests were separated using a pulse ramp of $10-80 \mathrm{~s}$ at $5.5 \mathrm{~V} \mathrm{~cm}^{-1}$ for $53 \mathrm{~h}$, unless otherwise specified. To separate PacI genomic DNA fragments, two windows of separation were utilized, first using a pulse ramp of $10-80 \mathrm{~s}$ at $5.5 \mathrm{~V} \mathrm{~cm}^{-1}$ for $30 \mathrm{~h}$ and then using a pulse ramp of $5-10 \mathrm{~s}$ at $5 \cdot 0 \mathrm{~V} \mathrm{~cm}^{-1}$ for $30 \mathrm{~h}$.

Southern blotting and DNA probes. Following PFGE, agarose gels were prepared as unblots (Tsao et al., 1983). The gels were incubated twice for $30 \mathrm{~min}$ in denaturation solution $(0.5 \mathrm{M} \mathrm{NaOH}, 1.5 \mathrm{M} \mathrm{NaCl})$ and twice for $30 \mathrm{~min}$ in neutralization solution (1.5 M NaCl, $1 \mathrm{M}$ Tris/ $\mathrm{HCl}, \mathrm{pH} 8.0$ ). After neutralization, the gels were dried under vacuum, first without heat for $30 \mathrm{~min}$ and then at $80^{\circ} \mathrm{C}$ for $1 \mathrm{~h}$. The dried gels (unblots) containing the DNA were subsequently probed in a Southern hybridization analysis as described by O'Toole $e t$ al. (1994). The DNA fragments utilized as probes in Southern blotting experiments were either cloned A. salmonicida genes, heterologous genes from $E$. coli or PCR fragments amplified using primers designed from published gene sequences of $A$. salmonicida. The PCR reactions were performed as previously described (Umelo \& Trust, 1997). The amplified DNA fragments were confirmed by sequencing and then labelled for use as probes using standard methodology (Umelo \& Trust, 1997).

Cloning of fragments from Pmel, Pad and I-Ceul genomic DNA digests. Specific A449 genomic DNA fragments obtained following either single or double digestion with I-CeuI, PacI and PmeI, were excised under low wavelength UV light. The pieces of agarose containing the DNA were individually incubated in $100 \mu \mathrm{l} 1 \times \mathrm{NEB}$ buffer 3 twice on ice for $30 \mathrm{~min}$. The solution was replaced with a fresh $100 \mu \mathrm{l}$ of NEB buffer 3 containing $20 \mathrm{U}$ each of PstI and BglII, incubated 
Table 1. Bacterial strains and vector used in this study

\begin{tabular}{|c|c|c|}
\hline Species & Strain & Source (other strain designations) \\
\hline \multirow[t]{9}{*}{ Typical A. salmonicida } & A449 & Brown trout, Eure, France \\
\hline & $\mathrm{A} 450$ & Brown trout, Tarn, France \\
\hline & A 488 & Brook trout, USA \\
\hline & A505 & Salmonid fish, Japan \\
\hline & A202 & Salmonid fish, Japan \\
\hline & $\mathrm{A} 251$ & Atlantic salmon, UK (ex-NCMB 1102) \\
\hline & A440 & Brook trout, USA \\
\hline & A438 & British Columbia, Canada \\
\hline & A447 & Salmonid, Weymouth, UK \\
\hline \multirow[t]{16}{*}{ Atypical A. salmonicida } & A400 & Goldfish, Boolara, Australia \\
\hline & A402 & Goldfish, Boolara, Australia \\
\hline & A419 & Goldfish, Arkansas, USA \\
\hline & A491 & Goldfish, Maryland, USA \\
\hline & A460 & Atlantic salmon, Nova Scotia, Canada \\
\hline & A461 & Atlantic salmon, Nova Scotia, Canada \\
\hline & A462 & Atlantic salmon, Nova Scotia, Canada \\
\hline & A477 & European carp, Europe \\
\hline & A480 & European carp, The Netherlands \\
\hline & A475 & Norway \\
\hline & A522 & Herring, British Columbia, Canada \\
\hline & A523 & Herring, British Columbia, Canada \\
\hline & A588 & Atlantic cod, Nova Scotia, Canada \\
\hline & A600 & Shubunkin (Goldfish), Germany \\
\hline & A601 & Goldfish, Europe \\
\hline & $\mathrm{A} 602$ & Putative Aeromonas strain \\
\hline \multirow[t]{4}{*}{ A. bydrophila } & TF7 & Trout lesion, Quebec, Canada \\
\hline & Ah300 & Human diarrhoeal faeces \\
\hline & Ah30 & Salmonid fish, British Columbia, Canada \\
\hline & Ah55 & Salmonid fish, British Columbia, Canada \\
\hline \multirow[t]{2}{*}{ A. sobria biotype veronii } & As701 & Human septicaemia, USA \\
\hline & As702 & Human septicaemia, USA \\
\hline E. coli & $\mathrm{DH} 5 \alpha$ & Hanahan (1983) \\
\hline Vector & pBluescript & Stratagene \\
\hline
\end{tabular}

overnight at $4{ }^{\circ} \mathrm{C}$ and then at $37^{\circ} \mathrm{C}$ for $16-24 \mathrm{~h}$. After digestion, the agarose containing the DNA was broken into small pieces with a Pasteur pipette and PstI/BamHI-digested pBluescript was added to the sample. The DNA was extracted by phenol/chloroform extraction and precipitated by adding 0.1 vols $3 \mathrm{M}$ sodium acetate and 2 vols $100 \%$ ethanol followed by incubation at $-70^{\circ} \mathrm{C}$ for $1 \mathrm{~h}$. The DNA was recovered by centrifugation, air-dried and resuspended in water. An aliquot of the DNA sample was ligated, electroporated into $E$. coli $\mathrm{DH} 5 \alpha$ and plated on selection medium. Cloned DNA fragments were used as probes in Southern blotting.

\section{RESULTS}

\section{Estimation of chromosome size}

The genomic DNA of A. salmonicida A449, with an estimated G $+\mathrm{C}$ content of $55 \mathrm{~mol} \%$ (Belland \& Trust, 1988), was digested with various enzymes to identify those which cleaved rarely. While the majority of the enzymes cleaved the A449 chromosome into too many fragments, two enzymes that produced a few fragments suitable for size estimation were identified (Fig. 1). ICeuI, an intron-encoded enzyme which cleaves within the 23S rRNA-encoding gene $(r r l)$ (Gauthier et al., 1991; Liu et al., 1993b), cleaved the A449 chromosome into nine fragments, the estimated sizes of which were $2800 \cdot 00 \pm 10 \cdot 0,515 \cdot 25 \pm 3 \cdot 0,436 \cdot 50 \pm 2 \cdot 0,238 \cdot 06 \pm 2 \cdot 0$, $186 \cdot 50 \pm 2 \cdot 0,178 \cdot 50 \pm 3 \cdot 0,130 \cdot 94 \pm 2 \cdot 0,76 \cdot 50 \pm 2 \cdot 0$ and $48.00 \pm 3.0 \mathrm{~kb}$. PmeI, which cleaves an AT-rich octanucleotide site, produced 11 fragments from A449, the estimated sizes of which were $876 \cdot 00 \pm 3 \cdot 5,766 \cdot 00 \pm 4 \cdot 0$, $710 \cdot 81 \pm 2 \cdot 5, \quad 670 \cdot 00 \pm 2 \cdot 0, \quad 525 \cdot 50 \pm 1 \cdot 5, \quad 460 \cdot 75 \pm 5 \cdot 0$, $315 \cdot 60 \pm 3 \cdot 0,160 \cdot 75 \pm 2 \cdot 5,144 \cdot 00 \pm 2 \cdot 0,68 \cdot 00 \pm 3 \cdot 0$ and $10 \cdot 00 \pm 2.0 \mathrm{~kb}$. PacI also cleaved an AT-rich octanucleotide site and produced at least 22 fragments from the A449 genomic DNA (Fig. 1). However, some fragments generated by $P a c I$ digestion were used as tools to show the linkage between some PmeI- and I-CeuI-derived fragments, as discussed below. By comparing the total fragment sizes obtained using I-CeuI and PmeI, the mean size of the A. salmonicida A449 chromosome was estimated at $4658 \pm 30 \mathrm{~kb}$. 


\section{Construction of the I-Ceul physical map}

The I-CeuI physical map of the A. salmonicida A449 chromosome was deduced using a combination of complete and partial digestion. Partial I-CeuI digestion of the A449 chromosome yielded the nine expected fragments, in addition to fragments corresponding to combinations of flanking fragments (Fig. 2). The partial fragments were isolated, digested to completion with ICeuI and separated by PFGE adjacent to complete ICeuI A449 genomic digests to aid identification of the constituent fragments. Since the resultant digests were often too faint to be visualized after ethidium bromide staining, the fragments obtained after complete digestion of partial fragments were end-labelled with radioactive nucleotides prior to being analysed by PFGE. Other I-CeuI-derived partial fragments obtained in this study include $3+5 / 6,2+4+5 / 6$ and $1+5 / 6$ (data not shown). By comparison and alignment of the fragments obtained from complete digestion of the partials, the chromosomal order of the nine I-CeuI fragments was deduced as 1-5/6-3-7-9-8-5/6-4-2. Since Ceu5 and 6 migrated as a doublet under the separation conditions utilized in the partial digestion analysis, the identity of any fragment migrating at this size needed to be confirmed by a different approach.

\section{Confirmation of the position of Ceu5 and 6 in the I-Ceul physical map}

PacI-derived fragment 3 (Pac3) was used to confirm the position of Ceu 5 and 6 in the deduced order of the $A$. salmonicida A449 I-CeuI-derived DNA fragments. Cleavage of Pac3 with I-CeuI yielded three subfragments (data not shown). One of the subfragments migrated at the same size as Ceu4, suggesting that the other two subfragments were part of the I-CeuI-derived fragments flanking Ceu4 on the A449 chromosome. DNA fragments unique to each of the three subfragments were cloned and utilized as probes on A449 I-CeuI genomic digests. The probes hybridized to Ceu2, 6 and 4. Thus, $\mathrm{Pac} 3$ revealed the order of the I-CeuI-derived fragments in that region of the chromosome to be 6-4-2. This suggested that Ceu5 was located at position 1-5-3 on the I-CeuI cleavage map of A449 chromosome. That Ceu5 was indeed located beside Ceu1, and Ceu 6 beside Ceu4 was confirmed by the fact that digestion of Ceu6 with PacI yielded two subfragments, one of which corresponded to the same size as that obtained by the I-CeuI digestion of Pac3, while Ceu5 was not cleaved by PacI (data not shown). Therefore, the deduced order of the nine I-CeuI-derived fragments of A. salmonicida A449 chromosome was 1-5-3-7-9-8-6-4-2.

\section{Circularization of the I-Ceul physical map}

Because B. burgdorferi (Casjens \& Huang, 1993) and several Streptomyces species (Lin et al., 1993) have been shown to possess linear chromosomes, we sought to identify the conformation of the A. salmonicida A449 chromosome. Digestion of $\mathrm{Pac} 2$ with I-CeuI yielded two (a)

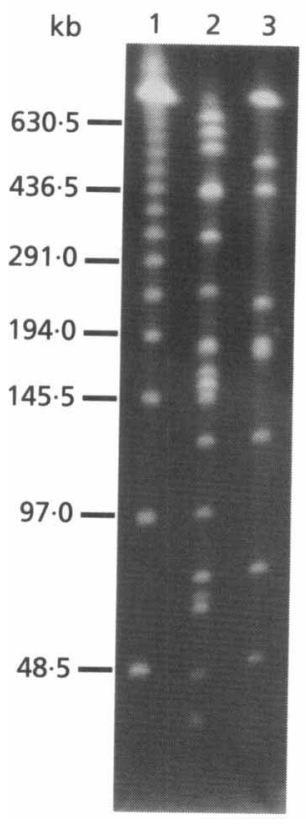

(b)

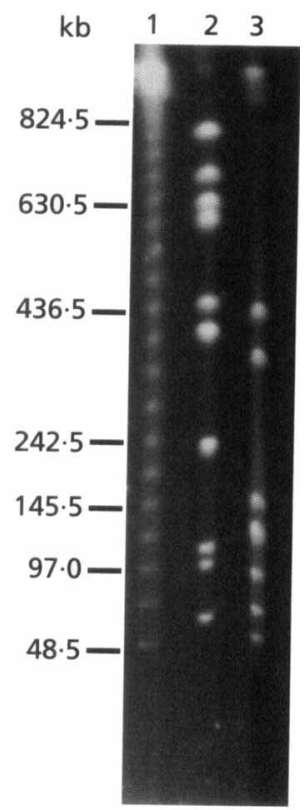

Fig. 1. Genomic DNA of $A$. salmonicida A449 digested using Pacl and I-Ceul (a), and Pmel and I-Ceul (b) separated on a 1\% agarose gel. (a) Lanes: $1, \lambda$ concatamer; 2 , Pacl digest; 3, I-Ceul digest. (b) Lanes: 1, $\lambda$ concatamer; 2, Pmel digest; 3, 1-Ceul digest. The DNA in (a) was separated first using a pulse ramp of $5-10 \mathrm{~s}$ for $30 \mathrm{~h}$ at $5.0 \mathrm{~V} \mathrm{~cm}^{-1}$ and then a $10-80 \mathrm{~s}$ pulse ramp for $30 \mathrm{~h}$ at $5.5 \mathrm{~V} \mathrm{~cm}^{-1}$. The DNA in (b) was separated using a pulse ramp of $10-80 \mathrm{~s}$ at $5.5 \mathrm{~V} \mathrm{~cm}^{-1}$ for $53 \mathrm{~h}$.

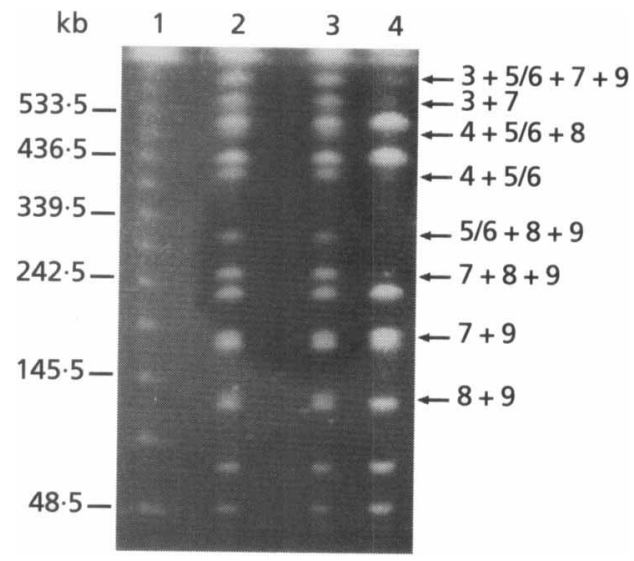

Fig. 2. Partial l-Ceul digestion analysis of the genome of $A$. salmonicida A449. Lane 1, $\lambda$ concatamer. In the lanes with the partial digests ( 2 and 3 ), digestion was terminated after 40 min and then analysed next to a complete digest (lane 4) conducted for $4 \mathrm{~h}$. The partial fragments are indicated by arrows and the constituent I-Ceul fragments are indicated on the right. The fragments were separated using a pulse ramp of 5-50 s at $185 \mathrm{~V} \mathrm{~cm}^{-1}$ for $20 \mathrm{~h}$ using a $0.7 \%$ agarose gel.

subfragments (data not shown). When DNA fragments cloned from each of the two Pac2 subfragments were used as probes on A449 I-CeuI digests, one hybridized to 


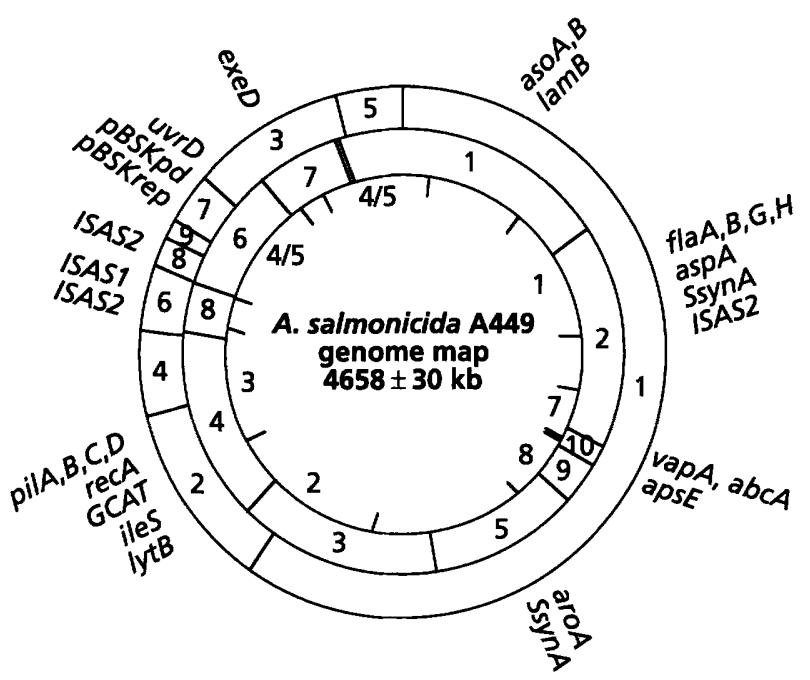

Fig. 3. Physical and genetic map of the A. salmonicida A449 chromosome constructed using I-Ceul and Pmel. The approximate locations of some genes are shown. The Pmel map is represented by the inner circle and the I-Ceul map by the outer circle. The bars inside the inner circle represent the approximate positions of the Pacl-derived DNA fragments used in linking the I-Ceul- and Pmel-derived fragments. The map was constructed using a combination of strategies such as partial and complete digestion analysis, alignment of fragments with common genes and use of fragments obtained with one enzyme as probes on the fragments obtained with the other enzymes.

Ceu1 while the other hybridized to Ceu2. This showed that A. salmonicida A449 possesses a circular chromosome and that Pac2 is located at the junction between Ceu1 and 2 (Fig. 3).

\section{Determination of the Pmel physical map and its alignment to the I-Ceul map}

The PmeI physical map was deduced and aligned to the I-CeuI map using several strategies. First, by comparing the I-CeuI- and PmeI-derived A449 genomic DNA fragments which had common genes (Table 2), 9 of the $11 \mathrm{Pmel}$ fragments were aligned to their corresponding positions around the deduced I-CeuI physical map (Fig. 3). The alignment also gave a good indication of the PmeI fragments which were likely to be linked.

Isolation of Ceu1 and digestion with PmeI yielded six subfragments, four of which migrated at the size as Pme2, 5, 9 and 10, while the other two subfragments did not correspond to any PmeI-derived A449 genomic DNA fragments, suggesting that these two subfragments originated from the PmeI fragments located at the junctions of the I-CeuI, with one between Ceu1 and Ceu5 and the other between Ceu1 and Ceu2. Use of the two subfragments as probes on PmeI digests revealed they constituted part of Pme1 and 3.

To confirm the linkage between adjacent PmeI fragments, PacI-derived fragments which contained PmeI sites were utilized. Pac1, 2, 4, 5, 7 and 8/9 contained
PmeI sites and therefore could be used to link adjacent PmeI-derived fragments. When used as probe, Pac1 hybridized to Pme1 and 2, Pac2 linked Pme3 and 4, Pac4 and 5 linked Pme1, 11,7 and 6, Pac7 linked Pme2 and 10, while Pac8/9 linked Pme10, 9 and 5. The PmeI fragment linkage order deduced using this approach was 6-7-11-12-10-9-5 and 3-4.

Finally, partial digestion analysis of A. salmonicida A449 with PmeI yielded several partial fragments, the size of two of which corresponded to Pme6 and 8, and Pme9 and 10. Thus, the PmeI cleavage map was shown to be 8-6-7-11-1-2-10-9-5. Since Pme8 hybridized to Ceu6 and Pme4 was localized to Ceu6, 4 and 2 by hybridization, this showed that the complete cleavage map of PmeI was 3-4-8-6-7-11-1-2-10-9-5. This accounted for the 11 PmeI fragments and the deduced linkage pattern was in agreement with the order predicted by comparison of $P m e \mathrm{I}$ and I-CeuI fragments with common genes. Since the A. salmonicida A449 chromosome has been deduced to be circular and the remaining linkage is localized within the single Ceu1 fragment, it follows that to complete the circle, Pme3 is linked to Pme5 (Fig. 3).

\section{Mapping of virulence factor-encoding genes and others}

Isolated genes of $A$. salmonicida were localized to the fragments generated by I-CeuI and PmeI by Southern blotting analysis. Radiolabelled $\lambda$ DNA was included in the hybridization cocktail to aid in identifying the fragment to which the genes hybridized. Table 2 shows the genes analysed and the I-CeuI- and Pmel-derived A449 chromosomal fragments to which they localized. Since relatively few genes of $A$. salmonicida have been characterized, heterologous genes of $E$. coli were also used as probes to localize the homologous copies of these genes on the A449 chromosome. Using this approach, the PmeI- and I-CeuI-derived fragments of A449 which contained DNA homologous to the E. coli genes encoding UvrD helicase II, LytB and isoleucyl tRNA synthase were identified (Table 2).

\section{Genomic comparison of Aeromonas strains}

To examine the genomic relationship between typical and atypical strains of $A$. salmonicida isolated from diverse geographical origins and from different fish diseases, the genomic I-CeuI digestion fingerprints of nine typical and 16 atypical strains were compared (Fig. 4). In addition, the I-CeuI digestion fingerprints of four strains of $A$. hydrophila and two $A$. sobria biotype veronii strains were also compared to $A$. salmonicida strains. I-CeuI produced nine fragments with nearly identical digestion fingerprints from the genome of the typical strains examined (Fig. 4a). In contrast, extensive polymorphism was observed in the number and size of the fragments obtained following digestion of the genome of the atypical strains with I-CeuI (Fig. $4 \mathrm{~b}$ and c, lanes 8-12), which is a good indication of significant genome diversity within this group. While nine of the atypical strains yielded nine fragments after I-CeuI 
Table 2. Location of genes on I-Ceul- and Pmel-derived DNA fragments of the A. salmonicida A449 chromosome

\begin{tabular}{|c|c|c|c|c|}
\hline I-CeuI & PmeI & Genotype & Phenotype & Reference \\
\hline 1 & 2 & $f l a A, B, G, H$ & Flagellar proteins & Umelo \& Trust (1997) \\
\hline 1 & 2 & aspA & Serine protease & Whitby et al. (1992) \\
\hline 1 & 1 & aso $A, B$ & Secretion protein & Noonan \& Trust (1996) \\
\hline 1 & 1 & $\operatorname{lamB}$ & Maltose-inducible porin & Dodsworth et al. (1993) \\
\hline 1 & 10 & $a p s E$ & A-protein specific secretion protein & Noonan \& Trust $(1995 b)$ \\
\hline 1 & 10 & $\operatorname{vap} A$ & A-protein subunit & Chu et al. (1991) \\
\hline 1 & 10 & $a b c A$ & Transcriptional activator & Chu \& Trust (1993) \\
\hline 1 & 5 & aroA & $\begin{array}{l}\text { 5-Enolpyruvylshikimate-3- } \\
\text { phosphate synthase }\end{array}$ & Vaughan et al. (1993) \\
\hline 2 & 4 & GCAT & $\begin{array}{l}\text { Glycerophospholipid-cholesterol } \\
\text { acyltransferase }\end{array}$ & Nerland (1996) \\
\hline 2 & 4 & pilA,B,C,D & Pilin subunit and prepilin peptidase & $\begin{array}{l}\text { P. Lutwyche and others } \\
\text { (unpublished data) }\end{array}$ \\
\hline 2 & 4 & $\operatorname{rec} A$ & RecA protein & Umelo et al. (1996) \\
\hline 2 & 4 & lytB & Signals starvation stress & Gustafson et al. (1993) \\
\hline 2 & 4 & ileS & Isoleucyl-tRNA synthase & Innis et al. (1984) \\
\hline 3 & 7 & exeD & Secretion protein & Karlyshev \& McIntyre (1995) \\
\hline 6 & 8 & ISAS1 & Insertion sequence & Gustafson et al. (1994) \\
\hline 7 & 6 & $u v r D$ & UvrD Helicase 11 & This study \\
\hline 7 & 6 & $p B S K p d$ & Phosphogluconate dehydratase & This study \\
\hline 7 & 6 & pBSKrep & Possible repressor & This study \\
\hline \multicolumn{5}{|c|}{ Genes present on multiple fragments } \\
\hline 1 & 2,5 & SsynA & Siderophore synthase homologue & This study \\
\hline $1,6,8$ & $2,6,8$ & ISAS2 & Insertion sequence & Gustafson et al. (1994) \\
\hline $2,3,4,5,6,7,8,9$ & $1,3,4,6$ & $r r s$ & $16 \mathrm{~S}$ rRNA & Martinez-Murcia et al. (1992) \\
\hline $1,2,3,4,5,6,7,8,9$ & $1,3,4,6$ & $r r l$ & $23 S$ rRNA & This study \\
\hline
\end{tabular}

digestion, A480 yielded 10 fragments, A600, A460, A461 and A462 yielded eight fragments, A475 yielded seven fragments and $\mathrm{A} 602$ yielded three fragments.

Like the typical strains of $A$. salmonicida, A. sobria biotype veronii genomic DNA was also cleaved into nine fragments and the two strains examined had an identical I-Ceul digestion fingerprint (Fig. 4c, lanes 2 and 3 ). There was also an observed similarity in size between the five smallest fragments of the A. sobria strains in comparison with the typical strains of $A$. salmonicida. In contrast, $A$. bydrophila strains showed polymorphism similar to that observed within the atypical strains of $A$. salmonicida (Fig. 4c, lanes 4-7). A. bydrophila strains Ah30 (lane 6) and Ah55 (lane 7) yielded 10 fragments upon digestion with I-CeuI, TF7 yielded eight fragments (lane 4) while Ah300 yielded seven fragments (lane 5). The I-CeuI digestion fingerprints of TF7 and Ah300 were practically identical, with the exception of the additional fragment produced from the TF7 genome.

\section{DISCUSSION}

This study presents the first chromosomal map of an Aeromonas species to be determined. The known genes which encode proteins implicated in the pathogenesis of
A. salmonicida A449, such as aspA, aroA, vapA and $G C A T$, are dispersed around the circular chromosome. The exe genes encoding proteins of the general secretory system and apsE encoding a protein involved in the specific transport of VapA, the subunit protein for the A-layer, are also far apart on the chromosome, showing a distinction in location in addition to function. While it was known that $a b c A$, which encodes a protein involved in vapA regulation and LPS biosynthesis, was immediately downstream of $v a p A$ (Chu \& Trust, 1993), the location of the apsE relative to the $v a p A-a b c A$ loci was unknown. The map shows that $\nu a p A, a b c A$ and $a p s$ are clustered. The recently identified fla (Umelo \& Trust, $1997)$ and pilin genes (P. Lutwyche and others, unpublished data) are widely separated on the $A$. salmonicida A449 chromosome. The two endogenous IS elements ISAS1 and ISAS2 of A. salmonicida (Gustafson et al., 1994) are clustered with the exception that one of the three copies of $I S A S 2$ is located at a site distant from the others. While the copy numbers of ISAS1 and ISAS2 in the A. salmonicida chromosome were previously unknown, this study has revealed that there are at least three copies of ISAS2 and possibly only one of ISAS1.

The attenuation of $A$. salmonicida by growth at high temperature was reported to be a result of insertion of ISAS1 and ISAS2 into vapA and its flanking DNA 

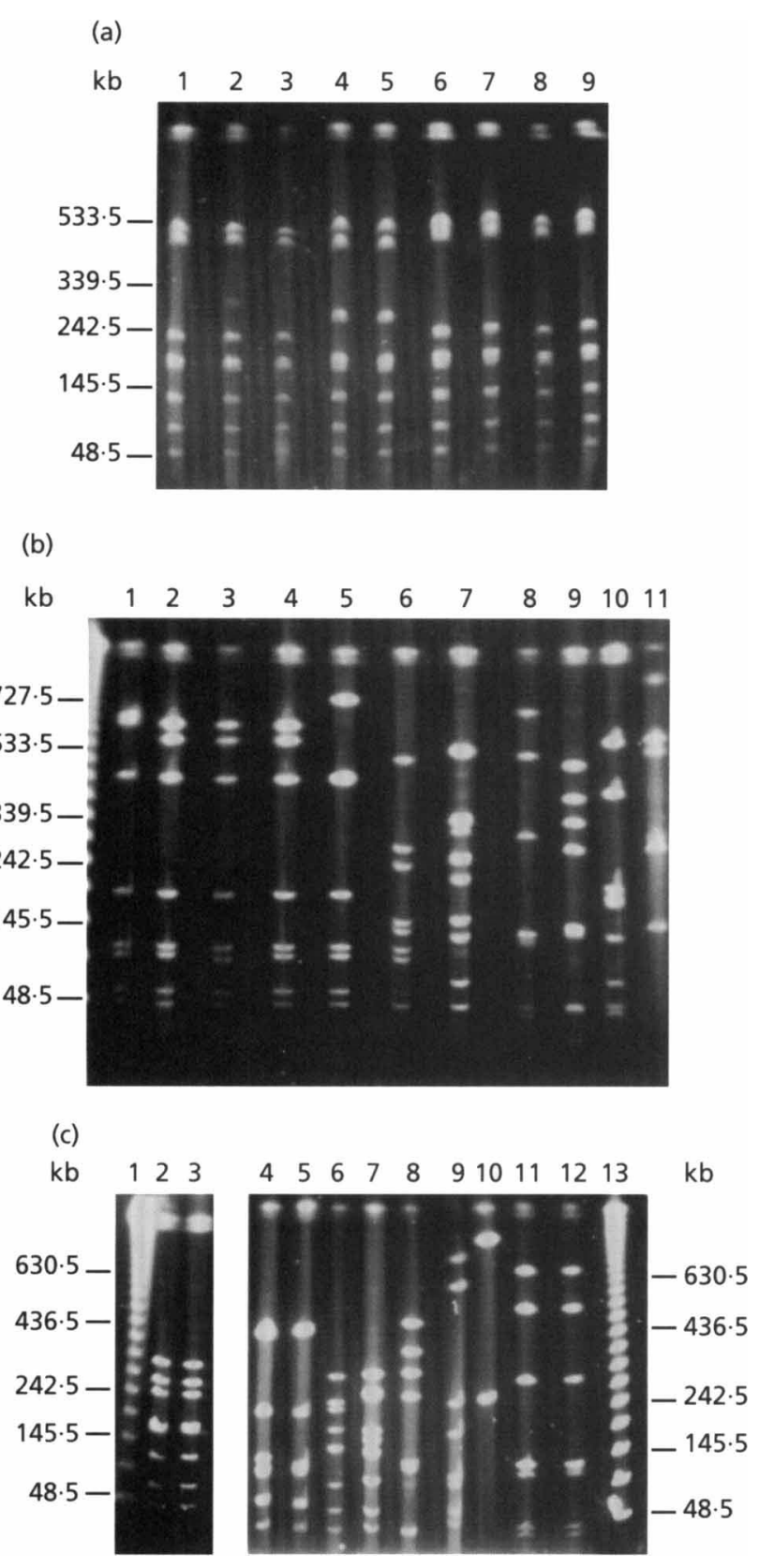

Fig. 4. Comparison of the I-Ceul genomic digestion fingerprint of Aeromonas strains. (a) Typical $A$. salmonicida strains. Lanes: 1, A449; 2, A450; 3, A488; 4, A505; 5, A202; 6, A251; 7, A440; 8, A438; 9, A447. (b) Atypical $A$. salmonicida strains. Lanes: 1 , A419; 2 , A402; 3, A400; 4, A491; 5, A600; 6, A477; 7, A588; 8, A461; 9, A522; 10, A480; 11, A475. (c) Strains of other Aeromonas species. Lanes: $1, \lambda$ concatamer; 2 and $3, A$. sobria biotype veronii strains As701 (2) and As702 (3); 4-7, A. hydrophila strains TF7 (4), Ah 300 (5), Ah30 (6) and Ah55 (7); 8-12, atypical strains of $A$. salmonicida A523 (8), A601 (9), A602 (10), A462 (11) and A460 (12); 13, $\lambda$ concatamer. The DNA fragments were separated in a $1 \%$ agarose gel using a pulse ramp of 5-90s at $185 \mathrm{~V} \mathrm{~cm}^{-1}$ for $28 \mathrm{~h}$.

(Gustafson et al., 1994). In this regard, it is of interest to note the chromosomal relationship between vapA and the IS elements. Although one copy of ISAS2 is located in the vicinity of $v a p A$, two copies of ISAS2 and the only copy of $I S A S 1$ are located approximately $2300 \mathrm{~kb}$ from $v a p A$, yet they are both capable of translocating into $v a p A$ and its flanking DNA. This suggests interesting mechanisms for endogenous mutation.

The near constant I-CeuI digestion fingerprint of the typical strains of $A$. salmonicida analysed in this study confirms the homogeneity within this group as previously suggested (Belland \& Trust, 1988; Boyd et al., 1994; Nielson et al., 1993). Because these typical strains were obtained from diverse geographical locations, these results provide further evidence that the genome of $A$. salmonicida is quite stable and also supports the suggestion that the population structure of typical strains is clonal (Boyd et al., 1994). In contrast, the I$\mathrm{CeuI}$ digestion fingerprints of the atypical $A$. salmonicida strains varied extensively, although there were clearly closer relationships between some strains than others. For example, A. salmonicida A400, A402, A419, A491, A600 and A601 which were all isolated from diseased goldfish from either Australia, USA or Europe had nine fragments in similar I-CeuI digestion fingerprints. These results therefore suggested a clonality for the goldfish isolates. These observations are in agreement with an earlier study by Belland \& Trust (1988) which reported as much as $99 \pm 3.0 \%$ homology between goldfish isolates from one location which had only an estimated $79 \pm 2.9 \%$ identity with atypical strains isolated from other diseases and locations. From that study, Belland \& Trust reported distinct groups corresponding to isolates from goldfish and carp. In this study, we examined two isolates from carp, A480 and A477. In contrast to the reported similarity between the carp isolates observed using the DNA-DNA hybridization technique, we did not observe a similarity between the I-CeuI digestion fingerprints of the two carp isolates examined. Not surprisingly, another group of strains which appeared to be clustered were A460, A461 and A462 which were all isolated from a single disease outbreak in Atlantic salmon in Nova Scotia, Canada.

The I-CeuI digestion fingerprints of the rest of the atypical strains examined in this study were highly variable and could not be grouped, suggesting they have diverged from other atypical strains. While firm conclusions cannot be made, considering the number of strains analysed in this study, the results suggest that comparison of the I-CeuI digestion fingerprints could help identify related strains and thus help to better classify and subdivide the atypical strains. By comparison of the I-Ceul digestion fingerprints, the $A$. sobria biotype veronii strains were more closely related to $A$. salmonicida strains than were the four $A$. bydrophila strains.

The variability in the number of fragments obtained from the I-CeuI digestion of atypical strains of $A$. salmonicida and the $A$. hydrophila strains was a surprising finding. Such a variation, to our knowledge, has not been reported for any other species. Liu et al. (1993c) reported that recombination events occurring 
within the $r r n$ genes are common in bacteria and Sneath (1993) reported that genetic cross-overs have occurred between different Aeromonas species as a result of homologous recombination between rrs genes. It is possible that such recombination events, either within or between strains of different Aeromonas species, could lead to deletions or insertions, resulting in either an increase or decrease in the overall number of $r \mathrm{rn}$ operons. Differences in the number of $r r n$ operons have been reported in two different $R$ hodobacter species. Rhodobacter capsulatus strain SB1003 possessed four rrn operons (Fonstein et al., 1992) while Rhodobacter sphaeroides 2.4.1 possessed three rrn operons (Suwanto \& Kaplan, 1989). However, there is generally an observed intraspecies conservation in genome backbone and $r r n$ operons in species in which the genome maps of several strains have been constructed (reviewed by Cole \& Saint Girons, 1994). It is therefore tempting to speculate that some strains currently classified as atypical $A$. salmonicida may not belong in this species. This could be a possible explanation for the difficulties which have been encountered in the classification of atypical $A$. salmonicida strains and other strains within the genus Aeromonas.

A. salmonicida contains several endogenous plasmids (Toranzo et al., 1983). In A. salmonicida A449, three small plasmids of $5 \cdot 0,5 \cdot 2$ and $5 \cdot 4 \mathrm{~kb}$ and a large plasmid of approximately $145 \mathrm{~kb}$ have been reported (Belland $\&$ Trust, 1989). The results obtained in this study show that these endogenous plasmids did not interfere in the linkage of both the I-CeuI- and PmeI-derived A. salmonicida A449 chromosomal DNA fragments. While the three small plasmids probably migrated off the gel under the conditions used in this study, the large plasmid might not. Indeed, a very faint band migrating at approximately $150 \mathrm{~kb}$ was sometimes seen in overloaded lanes containing I-CeuI digests and could be the linearized $145 \mathrm{~kb}$ plasmid of A. salmonicida A449. Neither of the genes used as probes in Southern analysis nor any of the fragments obtained during the I-CeuI partial digestion analysis hybridized to the faint apparent plasmid band.

The information provided in the map will be useful for the rational development of a live attenuated $A$. salmonicida vaccine strain. The map will also be useful for comparison of the chromosomal organization of Aeromonas species as more strain maps are determined. Finally, we have identified a tool that could have significant consequences in Aeromonas taxonomy, either in confirming the current classification of strains or in recognizing new isolates.

\section{ACKNOWLEDGEMENTS}

This study was supported in part by grants to T. J.T from the National Centers of Excellence as part of the Canadian Bacterial Disease Network Research Program. We are very grateful to Dr Edward E. Ishiguro for providing us with E. coli gene probes, Dr Francis Nano for use of equipment and Dr Diane E. Taylor for helpful comments.

\section{REFERENCES}

Austin, B. \& Austin, D. A. (1993). Aeromonadaceae representatives (Aeromonas salmonicida). In Bacterial Fish Diseases: Disease in Farmed and Wild Fish, pp. 86-170. Edited by B. Austin \& A. Austin. Chichester: Ellis Horwood.

Austin, D. A., Mclntosh, D. \& Austin, B. (1989). Taxonomy of fishassociated Aeromonas spp. with the description of Aeromonas salmonicida subsp. smithia subsp. nov. Syst Appl Microbiol 11, 277-290.

Belland, R. J. \& Trust, T. J. (1988). DNA:DNA reassociation analysis of Aeromonas salmonicida. J Gen Microbiol 134, 307-315.

Belland, R. J. \& Trust, T. J. (1989). Aeromonas salmonicida plasmids: plasmid-directed synthesis of proteins in vitro and in Escherichia coli minicells. J Gen Microbiol 135, 513-524.

Boyd, E. F., Hiney, M. P., Peden, J. F., Smith, P. R. \& Caugant, D. A. (1994). Assessment of genetic diversity among Aeromonas salmonicida isolates by multilocus enzyme electrophoresis. J Fish Dis 17, 97-98.

Casjens, S. \& Huang, W. M. (1993). Linear chromosomal physical and genetic map of Borrelia burgdorferi, the lyme disease agent. Mol Microbiol 8, 967-980.

Chu, S. \& Trust, T. J. (1993). An Aeromonas salmonicida gene which influences A-protein expression in Escherichia coli encodes a protein containing an ATP-binding cassette and maps beside the surface array protein gene. J Bacteriol 175, 3105-3114.

Chu, S., Cavaignac, S., Feutrier, J., Phipps, B. M., Kostrzynska, M., Kay, W. W. \& Trust, T. J. (1991). Structure of the tetragonal surface virulence array protein and gene of Aeromonas salmonicida. J Biol Chem 266, 15258-15265.

Cole, S. T. \& Saint Girons, I. (1994). Bacterial genomics. FEMS Microbiol Rev 14, 139-160.

Dodsworth, S. J., Bennet, A. J. \& Coleman, G. (1993). Molecular cloning and nucleotide sequence analysis of the maltose inducible porin gene of Aeromonas salmonicida. FEMS Microbiol Lett 112, 191-198.

Fonstein, M., Zheng, S. \& Haselkorn, R. (1992). Physical map of the genome of Rhodobacter capsulatus SB 1003. J Bacteriol 174, $4070-4077$.

Gauthier, A., Turmel, M. \& Lemieux, C. (1991). A group I intron in the chloroplast large subunit rRNA gene of Chlamydomonas eugametos encodes a double-strand endonuclease that cleaves the homing site of this intron. Curr Genet 19, 43-47.

Gustafson, C. E., Kaul, S. \& Ishiguro, E. E. (1993). Identification of the Escherichia coli lytB gene, which is involved in penicillin tolerance and control of the stringent response. J Bacteriol 175, 1203-1205.

Gustafson, C. E., Chu, S. \& Trust, T. J. (1994). Mutagenesis of the paracrystalline surface protein array of Aeromonas salmonicida by endogenous insertion elements. $J \mathrm{Mol}$ Biol 237, 452-463.

Hanahan, D. (1983). Studies on transformation of Escherichia coli with plasmids. $J$ Mol Biol 166, 557-580.

Innis, M. A., Tokunaga, M., Williams, M. E., Loranger, J. M., Chang, S.-Y., Chang, S. \& Wu, H. C. (1984). Nucleotide sequence of the Escherichia coli prolipoprotein signal peptidase (lsp) gene. Proc Natl Acad Sci USA 81, 3708-3712.

Karlyshev, A. V. \& Mclntyre, S. (1995). Cloning and study of the genetic organization of the exe cluster of Aeromonas salmonicida. Gene 158, 77-82.

Lin, Y.-S., Kieser, H. M., Hopwood, D. A. \& Chen, C. W. (1993). 
The chromosomal DNA of Streptomyces lividans 66 is linear. Mol Microbiol 10, 923-933.

Liu, S.-L., Hassel, A. \& Sanderson, K. E. (1993a). The $\mathrm{X} b a \mathrm{I}-\mathrm{B} \ln \mathrm{I}-\mathrm{C} e u \mathrm{I}$ genomic cleavage map of Salmonella enteritidis shows an inversion relative to Salmonella typhimurium LT2. Mol Microbiol 9, 655-664.

Liu, S.-L., Hessel, A. \& Sanderson, K. E. (1993b). Genomic mapping with I-CeuI, an intron-encoded endonuclease specific for genes for ribosomal RNA, in Salmonella spp., Escherichia coli and other bacteria. Proc Natl Acad Sci USA 90, 6874-6878.

Liu, S.-L., Hessel, A. \& Sanderson, K. E. (1993C). The

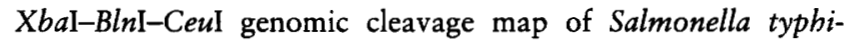
murium LT2 determined by double digestion, end labeling and pulsed field gel electrophoresis. J Bacteriol 175, 4104-4120.

Martinez-Murcia, A. J., Benlloch, S. \& Collins, M. D. (1992). Phylogenetic interrelationships of members of the genera Aeromonas and Plesiomonas as determined by $16 \mathrm{~S}$ ribosomal DNA sequencing: lack of congruence with results of DNA-DNA hybridizations. Int J Syst Bacteriol 42, 412-421.

Nerland, A. H. (1996). The nucleotide sequence of the gene encoding GCAT from Aeromonas salmonicida ssp. salmonicida. $J$ Fish Dis 19, 145-150.

Nielson, B., Olsen, J. E. \& Larson, J. L. (1993). Plasmid profiling as an epidemiological marker within Aeromonas salmonicida. Dis Aquat Org 15, 129-135.

Noonan, B. \& Trust, T. J. (1995a). Molecular analysis of an Aprotein secretion mutant of Aeromonas salmonicida reveals a surface layer-specific protein secretion pathway. $J \mathrm{Mol}$ Biol 248, 316-327.

Noonan, B. \& Trust, T. J. (1995b). The molecular biology of Aeromonas salmonicida. Annu Rev Fish Dis 5, 95-111.

Noonan, B. \& Trust, T. J. (1996). An Aeromonas salmonicida gene required for the establishment of infection in rainbow trout (Oncorbynchus mykiss). Gene 175, 127-131.

O'Toole, P. W., Kostrzynska, M. \& Trust, T. J. (1994). Non-motile mutants of Helicobacter pylori and Helicobacter mustelae defective in flagellar hook production. Mol Microbiol 14, 691-703.

Schwartz, D. C., Saffran, W., Welsh, J., Haas, R., Goldenberg, M. \& Cantor, C. R. (1983). New techniques for purifying large DNAs and studying their properties and packaging. Cold Spring Harbor Symp Quant Biol 37, 189-195.

Smith, C. L., Econome, J. G. Schutt, A., KIco, S. \& Cantor, C. R. (1987). A physical map of the Escherichia coli K12 genome. Science 236, 1448-1453.

Smith, C. L., KIco, S. R. \& Cantor, C. R. (1988). Pulsed-field gel electrophoresis and the technology of large DNA molecules. In Genome Analysis: a Practical Approach, pp. 41-72. Edited by K. E. Davies. Oxford: IRL Press.

Sneath, P. H. A. (1993). Evidence from Aeromonas for genetic crossing-over in ribosomal sequences. Int J Syst Bacteriol 43, $626-629$.

Suwanto, A. \& Kaplan, S. (1989). Physical and genetic mapping of the Rhodobacter sphaeroides 2.4.1 genome: genome size, fragment identification and gene localization. J Bacteriol 171, 5840-5849.

Toranzo, A. E., Barja, J. L., Colwell, R. R. \& Hetrick, F. M. (1983). Characterization of plasmids in bacterial fish pathogens. Infect Immun 39, 184-192.

Tsao, S. G. S., Brunk, C. F. \& Perlman, R. E. (1983). Hybridization of nucleic acids directly in agarose gels. Anal Biochem 131, 365-372.

Umelo, E. \& Trust, T. J. (1997). Identification and molecular characterization of two tandemly located flagellin genes from Aeromonas salmonicida A449. J Bacteriol 179, 5292-5299.

Umelo, E., Noonan, B. \& Trust, T. J. (1996). Cloning, characterization and expression of the recA gene of Aeromonas salmonicida. Gene 175, 133-136.

Vaughan, L. M., Smith, P. R. \& Foster, T. J. (1993). An aromaticdependent mutant of the fish pathogen Aeromonas salmonicida is attenuated in fish and is effective as a live vaccine against the salmonid disease furunculosis. Infect Immun 61, 2172-2181.

Whitby, P. W., Landon, M. \& Coleman, G. (1992). The cloning and nucleotide sequence of the serine protease gene (aspA) of Aeromonas salmonicida spp. salmonicida. FEMS Microbiol Lett 99, 65-72.

Wilcox, M. H., Cook, A. M., Thickett, K. J., Eley, A. \& Spencer, R. C. (1992). Phenotypic methods for speciating clinical Aeromonas isolates. J Clin Pathol 45, 1079-1083.

Received 13 January 1998; revised 22 April 1998; accepted 1 May 1998. 